\title{
LA DISPONIBILIDAD EN LOS BIENES JURÍDICOS
}

\author{
IGNACIO E. ACKERMANN HORMAZÁBAL \\ MARÍA FERNANDA OVALLE DONOSO ${ }^{2}$
}

\section{Resumen}

La disponibilidad tradicionalmente se ha predicado de los bienes jurídicos, de manera que ciertos bienes serían esencialmente indisponibles para su titular. A partir de la constatación del problema que enfrenta la concepción tradicional para explicar la indisponibilidad de ciertos bienes individuales, este trabajo propone una concepción de la disponibilidad que permita armonizar sus fundamentos con el ejercicio de ciertos bienes jurídicos en el marco de un Estado democrático de Derecho.

\section{Palabras Clave}

Disponibilidad - consentimiento - bienes jurídicos individuales

\begin{abstract}
Availability has traditionally been predicated regarding on legal assets, so that certain assets would be essentially unavailable to the owner.

Starting from the verification of the problem facing the traditional conception to explain the unavailability of certain individual rights, this work proposes a conception of availability that allows to harmonize its basics with the exercise of certain legal rights within the framework of a democratic State o Law.

1 Licenciado en Ciencias Jurídicas. Profesor ayudante del Departamento de Ciencias Penales, Escuela de Derecho de la Universidad de Valparaíso, Chile. Dirección electrónica: ignacio.ackermann@gmail.com

2 Licenciada en Ciencias Jurídicas. Profesora ayudante del Departamento de Ciencias Penales, Escuela de Derecho de la Universidad de Valparaíso. Profesora ayudante, mismo departamento, Universidad Andrés Bello (sede Viña del Mar), Chile. Dirección electrónica: Mf.ovalle@gmail.com
\end{abstract}




\section{Key Words}

availability - consent - legal assets

\section{Sumario}

1.- Estado actual de la cuestión. - 2.- Fundamento de la disponibilidad.- 3.-Problemas en torno a la vida y la salud individual.- - 4.- La disponibilidad en los bienes jurídicos. -5 . Resumen conclusivo.

\section{Estado actual de la cuestión}

La disponibilidad relativa a los bienes jurídicos es un concepto cuya importancia no se ve reflejada por el grado de desarrollo que ha tenido en la doctrina. En lo sucesivo, intentaremos abordar la disponibilidad como tal, precisando algunas dificultades que conviene tener presente para caracterizarla correctamente.

Un primer problema viene dado por el hecho de que normalmente se la ha tratado a partir del consentimiento, dada la íntima vinculación que existe entre ambos. Sin embargo, debe tenerse presente que ésta podría también operar fuera de aquel supuesto, como mera renuncia al objeto del bien jurídico. Para comprender esto es útil echar mano a la distinción alemana entre los llamados casos de hétero-lesión o hétero-puesta en peligro y de auto-lesión o auto-puesta en peligro. En los primeros casos, vale decir, cuando la ofensa es llevada a cabo por un tercero con la concurrencia de la voluntad del titular del bien jurídico, la disponibilidad adopta la forma de consentimiento, mientras que cuando en la lesión o puesta en peligro no existe intervención de terceros, la disponibilidad sería un acto de mera renuncia al objeto del bien jurídico por parte de su titular ${ }^{3}$, resultando que su campo de aplicación no puede restringirse sólo al consentimiento, lo que desaconseja la identificación de ambos conceptos. Sin perjuicio de lo anterior debe reconocerse que el consentimiento resulta ser la institución paradigmática a través de la cual se ejerce la disponibilidad y, considerando que la doctrina suele incluirla en el análisis del consentimiento, téngase presente que para extraer el contenido de la disponibilidad habremos de recurrir al desarrollo dogmático del consentimiento allí donde su revisión sea útil.

3 CANCIO MELIÁ, Manuel: Conducta de la Víctima e Imputación objetiva en el Derecho penal. Editorial J. M. Bosch, Madrid, $1^{\circ}$ ed., 1998. p. 46. 
En seguida, surgen dificultades al preguntarse qué implica la disponibilidad como tal. Ocurre que alguna opinión ha pretendido reconocer en ella dos acepciones distintas, diferenciando aquella que la relaciona a la posibilidad de disfrutar de un bien -es decir, tenerlo a disposición y aprovecharlo-de aquella que la vincula a la facultad o capacidad para renunciar a él o ponerlo en manos de un tercero, por la voluntad o consentimiento de su titular ${ }^{4}$, siendo sólo ésta última la relevante para el problema relativo al Derecho Penal. Sin embargo, tal distinción parece artificiosa toda vez que es precisamente la consideración de cada una de aquellas dimensiones a la luz de la otra lo que permite dotar de contenido la disponibilidad, pues para que el sujeto esté facultado para disfrutar del bien con el que se relaciona, es menester considerar también la posibilidad que le asiste de renunciar a él. De lo contrario, más que otorgarse una facultad, el ordenamiento estaría proscribiendo una forma dada de relacionarse con tal objeto. Dicho de otro modo, no es posible escindir la disponibilidad pues ésta, para ser tal, necesariamente ha de reunir tanto la facultad de renunciar como la de gozar de aquello de lo que se dispone.

Por último, parece evidente que la disponibilidad no puede tratarse separadamente de su objeto, es decir, se habla de disponibilidad en función de aquello de lo que se dispone. Pero tampoco se ha entendido de manera uniforme cuál es el objeto de aquella disposición. Tradicionalmente se ha concebido, con mayor o menor claridad, que el objeto de la disposición es el bien jurídico, lo que se desprende a partir del tratamiento dogmático que se le ha dado al consentimiento. En efecto, hay autores, como MAURACH y ZIPF, que lo han caracterizado como la "renuncia a un bien jurídico" bajo el epígrafe titulado, de similar manera, como "La renuncia a un bien jurídico ("consentimiento")"'. Pero la misma consideración puede encontrarse, aunque no tan explícitamente, tras los razonamientos utilizados al enfrentar el problema del ámbito de aplicación del consentimiento, donde es común que se haga depender su eficacia de la clasificación del bien jurídico según su titular, entre individuales, colectivos o estatales, entendiendo que sólo podrán ser disponibles los bienes jurídicos individuales -y no en todos los casos-, indicando que lo disponible o indisponible, es decir, el objeto de

$4 \quad$ CURBELO SOLARI, Ignacio: "Problemática sobre la disponibilidad de los Bienes Jurídicos Individuales y Responsabilidades Emergentes". En Revista de la Facultad de Derecho, No 32, Montevideo, 2012. pp. 89-90.

$5 \quad$ MAURACH, R., ZIPF, H.: Derecho Penal. Parte general, trad. $7^{\circ}$ ed. por Jorge Bofill Genzsch y Enrique Aimone Gibson. Astrea, Buenos Aires, 1994. p. 287 
la disponibilidad, sería el bien jurídico ${ }^{6}$. Es esta la postura más tradicional sobre el consentimiento, sin desconocer que existen otras varias visiones al respecto ${ }^{7}$.

\section{Fundamento de la disponibilidad}

La pregunta acerca de la disponibilidad está condicionada por una determinada concepción que es, ante todo, de orden político ${ }^{8}$. La disponibilidad del bien jurídico ha de tener relevancia en los hechos punibles contra el individuo pues, en este ámbito, un ordenamiento respetuoso de la dignidad y libertad de los sujetos permite a cada cual adoptar sus decisiones según sus propias representaciones valorativas y los fines por él seguidos?. Un derecho penal liberal tenderá a otorgar relevancia al consentimiento del individuo, mientras que un derecho menos celoso de la dignidad y libertad del hombre tenderá a limitar su alcance ${ }^{10}$. El respeto de la autodetermina-

6 Así, Mezger señala que éste tendría efectos solo en el ámbito de los bienes jurídicos de los cuales se pueda disponer, en MEZGER, Edmund: Derecho penal. Parte general. trad. $6^{\circ}$ ed. alemana por Conrado A. Finzi. Editorial Bibliográfica Argentina, Buenos Aires, 1954. p. 164. Del mismo modo refiere JESCHECK que "el consentimiento sólo puede entrar en consideración en relación a los bienes jurídicos individuales", en JESCHECK, Hans-Heinrich: Tratado de Derecho Penal. Parte general, trad. S. Mir Puig y F. Muñoz Conde. Bosch, Barcelona, 1981. p. 517

$7 \quad$ Existen autores que han visto en el consentimiento una renuncia a la protección jurídica que asiste a un bien (Ver WELZEL, Hans: Derecho Penal Alemán. Editorial Jurídica de Chile, Santiago, $11^{\circ}$ edición, 1976. p. 139 y JAKOBS, Günther: Derecho Penal. Parte general, Fundamentos y teoría de la imputación, $2^{\circ}$ ed., trad. Joaquín Cuello Contreras y José Luis Serrano González de Murillo. Marcial Pons, Madrid, 1997, pp. 523 y ss.). Otra opinión entiende que representa una situación que, bajo determinados presupuestos, suprimiría la validez de la norma de prohibición respectiva, lo que implicaría conceptualmente comprenderlo como una causa de exclusión del injusto sui generis que, sin embargo, deja subsistente la lesión del bien jurídico (Ver KINDHÄUSER, Urs: Teoría de las normas y sistemática del delito. Ara editores, Lima, 2008. p. 17 y 18).

8 La estrecha relación que existe entre el Derecho Político y el Derecho Penal, por constituir el primero la concepción a la que responde, da sustento y anima al segundo, a su vez responde a las diversas y sucesivas concepciones omnicomprensivas del mundo y de la vida y a la respectiva concepción del hombre. Una completa y precisa exposición sobre el punto puede encontrarse en RIVACOBA, Manuel de: "Orden político y orden penal". En: Revista Chilena de Derecho, vol. 22, №2, 1995. pp. 201-212. Las cuestiones que están tras la delimitación del ámbito de lo punitivo son consideraciones políticas e igual naturaleza posee la discusión acerca del consentimiento y la disponibilidad, que gran relevancia adquiere en la fijación de tales límites.

9 JESCHECK, ob. cit., p. 517.

10 CURBELO SOLARI, ob. cit., pp. 89-90; Del mismo modo, explica Mezger que "[e]n las épocas en que se sigue una orientación individualista, se extiende, por lo general, el ámbito del consentimiento eficaz, y, en cambio, en aquellas otras en que se destaca el valor de 
ción del sujeto implica renunciar a cualquier pretensión punitiva allí donde la disponibilidad, entendida como facultad, se ejerza libremente. De allí que surjan, entre otros, principios como el de ofensividad y de exclusiva protección de bienes jurídicos, como expresión del planteamiento general de intervención mínima, que exigen al derecho penal limitar su actividad únicamente a ciertos ataques contra bienes jurídicos, ocupando éstos un lugar destacado entre los límites impuestos al poder punitivo del Estado ${ }^{11}$. Por esta razón, en este acápite se hará breve referencia a la dignidad y la libertad como fundamentos de la disponibilidad.

La dignidad humana posee amplia capacidad argumentativa a favor de la disponibilidad y, concretamente, de la eficacia desincriminante del consentimiento. Solo diremos sobre ella que, como concepto moderno que deja atrás viejas concepciones subjetivas, ella no describe la realidad sino el deber ser de la misma, sirviendo como referente inicial y también como horizonte final de un derecho positivo justo ${ }^{12}$. El respeto absoluto que merece, consagrado en la Constitución de la República y en los pactos internacionales sobre derechos humanos, lleva a establecer ciertos límites en el derecho penal ${ }^{13}$, frente a lo que surge la necesidad de establecer su contenido. Al respecto, Clapham ha identificado al menos cuatro ámbitos en que ésta debe ser protegida o garantizada, de los cuales interesa particularmente aquél relativo a la "garantía de la posibilidad para la decisión individual y para las condiciones de realización de la autonomía y del propio proyecto de vida de cada individuo"14. Ello se torna relevante para fundamentar la facultad de cada cual para decidir sobre su propio plan de vida $-\mathrm{y}$, por qué no, del término de ésta- $\mathrm{y}$ de gozar de

la colectividad, se tiende a restringirlo". MEZGER, Edmund: Derecho penal. Parte general. trad. $6^{\circ}$ ed. alemana por Conrado A. Finzi. Editorial Bibliográfica Argentina, Buenos Aires, 1958. p. 163.

11 MIR PUIG, Santiago: El Derecho penal en el Estado Social y Democrático de Derecho. Ariel, Barcelona, 1994. p. 159.

12 PECES-BARBA MARTÍNEZ, Gregorio: La dignidad de la persona desde la Filosofia del Derecho. Editorial Dykinson, Madrid, $2^{\circ}$ ed., 2004. pp. 67 ss.

13 CURBELO SOLARI, ob. cit., pp. 89-90.

14 En efecto, Clapham identifica las siguientes: (1) la prohibición de todos los tipos de tratamiento inhumano, humillación o degradación por parte de una persona sobre otra; (2) la garantía de la posibilidad para la decisión individual y para las condiciones de realización de la autonomía y del propio proyecto de vida de cada individuo; (3) el reconocimiento de que la protección de la identidad grupal y cultural pueden ser esenciales para la protección de la dignidad personal; y (4) la creación de las condiciones requeridas para que cada individuo tenga sus necesidades individuales satisfechas. CLAPHAM, Andrew: Human Rights Obligations of Non-State Actors. Editorial Oxford, Oxford, 2006. p. 545-546. 
las condiciones para realizar aquello. En este sentido, la disponibilidad de bienes jurídicos se presenta como la vía en que se materializa dicha garantía: la vida es una serie de actos de disposición de bienes jurídicos, de los que disponemos para lograr los fines que individualmente consideramos valiosos y que se orientan a la realización de nuestra autonomía. Los discursos jurídicos modernos hacen referencia a un ser humano capaz de razonar y, por tanto, de cuidar su propia dignidad, de actuar de forma responsable y comedida, de reconocer criterios de juicio y de justicia comunes. Si el sujeto está imposibilitado de disponer de sus bienes, el Estado deja de garantizar las facultades inherentes a la dignidad de la persona, desconfianza insostenible en un Estado democrático. De esta manera, un derecho penal será respetuoso de la dignidad de las personas en la medida en que se les considere sujetos capaces de reconocer criterios de juicio y de actuar responsable y comedidamente, es decir, cuando otorgue al consentimiento (en tanto manifestación de la disponibilidad) el lugar que se merece, el de una eximente de la responsabilidad penal ${ }^{15}$.

Lamentablemente, autores han utilizado el razonamiento en sentido contrario: limitando la disponibilidad de bienes tomando como argumento la dignidad establecida como un límite ${ }^{16}$. Sin embargo, si no podemos disponer de nuestros bienes, entonces el Estado nos está ordenando el uso que éste determine, atentando contra la dignidad en la medida en que pretende crear sujetos ideales y con valores dados, no fruto de la confianza en la capacidad de autodeterminación que tiene cada individuo. Además, sabemos que la dignidad humana es fundamento de todos los derechos fundamentales y estos, a su vez, límites de la soberanía esta$\operatorname{tal}^{17}$, de manera que resultaría contradictorio castigar penalmente a quien ejecuta actos que implican la concreción de la voluntad que el propio titular ha manifestado al disponer de su bien, cuando el consentimiento que ha prestado cumpla con todos los requisitos que se exijan en el sistema jurídico de que se trate. A saber, convengamos en que los requisitos

15 LUTHER, Jörg: "Razonabilidad y dignidad humana”. En: Revista de Derecho Constitucional Europeo Universidad de Granada, España, año 4, núm. 7, enero-junio de 2007. pp. 3-4. 16 Es interesante notar que el respeto a la dignidad humana, consagrada en Constituciones Políticas y Tratados Internacionales, es invocado, precisamente, para establecer límites sobre la disposición autónoma de los bienes jurídicos individuales. En este sentido, LANGÓN, Miguel: Manual de Derecho penal. Editorial Del Foro, Montevideo, 2006. p. 313. 17 NOGUEIRA, Humberto: Dignidad de la persona, derechos fundamentales, bloque constitucional de derechos. p. 1-2. En http://www.crdc.unige.it/docs/articles/Dignidad.pdf 
del consentimiento son la capacidad para consentir ${ }^{18}$, su manifestación ${ }^{19}$, que se brinde oportunamente ${ }^{20}$ y no sea revocado ${ }^{21}$, y que la voluntad sea libre y consciente ${ }^{22}$.

De igual forma, la disponibilidad se funda en la libertad, concepto sumamente delicado atendido su contenido y alcance, y que ha ofrecido una amplísima gama de concepciones. No siendo este el lugar para extenderse sobre aquellas debe considerarse que, en tanto derecho fundamental, la libertad del sujeto no solo delimita una esfera de decisiones respecto de la cual debe mantenerse totalmente excluida la intervención estatal, sino que, además, implica que el Estado ha de promover el ejercicio de tal libertad

18 CEREZO MIR, José: Derecho penal. Parte General. Ed. Tecnos, Montevideo-Buenos Aires, 2008. p. 650.

19 MAURACH y ZIPF, ob. cit., p. 410.

20 Sobre la idea básica del instituto hay dos posturas. En primer lugar, aquella que sostiene que lo fundamental es que la intervención sea materialmente en interés del afectado, lo que implica, en palabras de Stratenwerth, "un paternalismo intolerable", pues el hecho de que se salvaguarden sus intereses no justifica en modo alguno la vulneración de su autodeterminación. Por otro lado, se fundamenta la idea básica, tal como se expone aquí, sobre la equiparación de la situación concreta a un consentimiento realmente otorgado, lo que no permite concluir vulneración alguna a la autodeterminación, sino por el contrario, ejercerla en lugar de otro, como si él lo hubiese hecho. STRATENWERTH, Günter: Derecho penal. Parte general I. El hecho punible, trad. $4^{\circ}$ ed. alemana por Manuel Cancio Meliá y Marcelo A. Sancinetti. Hammurabi, Buenos Aires, 2008. p. 221. En la primera postura, Welzel, para quien el fundamento preponderante es el actuar positivo en interés del afectado, resguardando solamente impedir una preocupación excesiva de terceros. WELZEL, Hans: Derecho penal. Parte general, trad. de Carlos Fontán Balestra, Roque. Depalma, Buenos Aires, 1956. p. 102 21 Si bien autores como Cerezo Mir (CEREZO MIR, ob. cit., p. 650) o Roxin (ROXIN, Claus: Derecho penal. Parte general, 2 vols., trad. $2^{\circ}$ ed. alemana por Diego- Manuel Luzón Peña, Miguel Díaz y García Conlledo y Javier de Vicente Remesal. Civitas, Madrid, 1997, t. I. p. 535) no se detienen en la precisión de que esto es así únicamente hasta la ejecución del hecho, sí lo hacen, por ejemplo, Wessels (WESSELS, Johannes: Derecho penal. Parte general, trad. $6^{\circ}$ ed. alemana por Conrado A. Finzi. Ediciones Depalma, Buenos Aires, 1980. p. 103) o Mezger (MEZGER, ob. cit., p. 165) y lo hacemos también aquí, pues parece importante dejar establecido que una revocación posterior del consentimiento implicaría abandonar en manos del sujeto pasivo la decisión sobre la tipicidad o antijuridicidad de la conducta una vez ya consumado el hecho y, por tanto, ya calibradas las circunstancias por parte del agente, lo que no sólo genera evidentes problemas culpabilidad, sino que también vulnera directamente el principio de legalidad en su precipitado técnico, es decir, en relación a la tipicidad.

22 Las consecuencias jurídicas derivadas de la concurrencia de vicios de la voluntad en sede penal no son las mismas que en el derecho civil. ROXIN, ob. cit., p. 544; JIMÉNEZ DE ASÚA, Luis: Tratado de Derecho penal. Losada, Buenos Aires, 1952. p. 596. fundamentalmente porque en sede civil los actos que adolecen de vicios son válidos hasta que se declare su nulidad, lo que queda a la libre voluntad de su manifestante -en el caso de la nulidad relativa, cuando el vicio es subsanable-, mientras que en sede penal se exige que el consentimiento sea eficaz en el momento del acto (si constituye delito). 
personal. Desde John-Stuart Mill se cuestiona la intervención estatal en las decisiones del individuo cuando éstas sólo representan un daño a sí mismo y no para los demás ${ }^{23}$. Correspondería a un derecho penal liberal asumir tales conclusiones, entendiendo que cualquiera sea la decisión que el individuo adopte en el marco de sus propios asuntos, por muy perjudicial que fuere, deben éstas mantenerse fuera del ámbito de injerencia del Estado, el cual, además, ha de reconocer y promover a través del ordenamiento jurídico el ejercicio de tal libertad. Por esta razón, MAURACH y ZIPF refieren que "el consentimiento (...) es una institución jurídica muy ilustrativa de la relación entre el Estado y sus ciudadanos, en especial a lo relativo al espacio de libertad que aquél reconoce a cada uno de éstos", arguyendo que la facultad de consentir se arraiga constitucionalmente en la garantía de libertad general de acción ${ }^{24}$, la cual importaría la posibilidad de renunciar a la protección penal de bienes, por lo que, en aquellos casos, la norma penal pasaría a un segundo plano debido a que el ordenamiento jurídico y social reconocen la primacía de la facultad de libre disposición de cada individuo ${ }^{25}$. Del mismo modo, Roxin estima que la eficacia desincriminante del consentimiento se infiere sobre todo e inmediatamente de la libertad de acción ${ }^{26}$. Desde otra perspectiva, KINDHÄUSER considera también que en el consentimiento la libertad general de acción tiene un rol fundamental, por cuanto sólo ha de limitarse o restringirse en función de intereses de protección particularmente importantes ${ }^{27}$. En fin, parece claro que la disponibilidad refleja el valor que representa el respeto de las decisiones adoptadas por el individuo, lo que

23

Referencia a su planteamiento de que, allí donde no exista un daño a terceros, el individuo es plenamente soberano sobre sí mismo, sobre su cuerpo y espíritu, por lo que el poder sólo podría justificadamente intervenir cuando ello tenga por finalidad evitar que se perjudique a los demás, pero jamás para evitar que se dañe a sí mismo. Por ello, sólo cuando "una parte de la conducta de una persona afecte perjudicialmente los intereses de otras, la sociedad tiene jurisdicción sobre ellas y puede discutirse si su intervención es o no favorable al bienestar social". MILL, John-Stuart: Sobre la Libertad. Alianza Editorial, Madrid, 2004. pp. 65-66 y 154-155.

24 Contemplada en el art. $2^{\circ}$ de la Constitución alemana, titulado "Libertad de acción y de la persona".

25 En la construcción de tal planteamiento se cita a Jescheck para explicar que "en el Estado de Derecho el ejercicio sin trabas de la libertad personal es considerado como un valor social" (MAURACH y ZIPF, ob cit., cfr. pp. 287 y 288).

26 ROXIN, ob. cit., pp. 517 y 518.

27 Esto no está referido a su idea sobre la libertad general de acción como presupuesto fundamental para construir un enunciado normativo concreto, en el sentido de que ésta representaría uno de los intereses coordinados en la norma junto a los intereses del titular del bien jurídico, sino más bien nos referimos a la concepción de la libertad general de acción como un bien constitucionalmente protegido en sí mismo al que se le otorga particular importancia. Para una comprensión acabada de la propuesta de Kindhäuser. KINDHÄUSER, ob. cit., pp. 13-38. 
permite reducir la arbitrariedad estatal ${ }^{28}$ y brindar seguridad jurídica a los ciudadanos, pues resultaría contradictorio que el ordenamiento considere como valor fundamental a la libertad y, por otro lado, castigue conductas que son expresión de ella, por mero voluntarismo.

Sin embargo, dada la amplia gama de concepciones sobre la libertad, se la ha utilizado también como argumento para negar la eficacia del consentimiento, o para nuestro caso, restringir la disponibilidad. Tras este razonamiento existiría un esfuerzo por salvaguardar las decisiones que debiese tomar el individuo de ser capaz de comportarse racionalmente, asumiendo, entonces, que ciertas decisiones sólo pueden ser tomadas por quien carece de tal capacidad. Así, se protegería la libertad individual dejando la decisión en manos del Estado, como tercero más capacitado que el mismo interesado para decidir racionalmente ${ }^{29}$. En la bibliografía jurídico-penal, la objeción se ha vinculado con el hecho de que la indisponibilidad de ciertos bienes jurídicos individuales se fundaría en la protección de la "autonomía a largo plazo", sacrificando para ello la "precipitación del momento" 30 , decisión que toma el legislador por los individuos ya en el plano abstracto y general de las normas. Mas estas lecturas suponen la posibilidad de identificar qué es lo universalmente racional, para todo individuo y en todas las situaciones, con lo que no podemos sino discrepar en tanto consideramos que las decisiones concretas a que personalmente se vea enfrentado un sujeto, ante todo representan un conflicto de valor solucionable únicamente por éste ${ }^{31}$. Argumentos de este tipo no hacen más que otorgar, siempre y en todos los casos, el carácter de precipitación o arrebato a aquellas decisiones en las que el sujeto opte por disponer del objeto de

28 Puede ser interesante revisar el planteamiento que Pettit, en su teoría de la libertad, postula respecto de lo arbitrario de la elección sobre un acto de interferencia estatal, la cual será formalmente arbitraria cuando no se considere en ella los intereses de los afectados $\mathrm{y}$, substantivamente arbitraria, cuando éste vaya efectivamente en contra de los intereses o de los juicios de las personas afectadas. PETTIT, Philip: Republicanismo. Una teoría de la libertad y del gobierno, trad. Toni Domènech. Paidós, Barcelona, 1999. p. 82.

29 Esta idea es quizá identificable con el concepto berlineano de libertad positiva como autorrealización, cuya completa formulación puede encontrarse en BERLIN, Isaiah: Cuatro ensayos sobre la libertad. Alianza Editorial, Madrid, 1993. pp. 243-247, concepción que, en todo caso, el autor expone para rechazarla.

30 CANCIO MELIÁ, M. y PÉREZ MANZANO, M.: "Principios del Derecho penal". En: Introducción al Derecho penal. Civitas, Navarra, 2 ed., 2015. p. 102.

31 Esto también fue claramente apuntado por Mill, quien argumentó que cada cual es el mejor juez de sus propios intereses, por cuanto la persona interesada es quien mayor información de su situación actual posee, teniendo más posibilidades de acertar respecto de sus intereses personales y su moral. MILL, ob. cit., pp. 155-156. 
interés jurídico-penal de una forma distinta a como el Estado pretende que se utilice. No hay razón para sentenciar de antemano que la elección libre de disposición del bien no pueda también ser una decisión racionalmente adoptada, lo que se salvaguarda, en primer término, con el establecimiento de los requisitos y exigencias para la disponibilidad y el consentimiento. Limitar la libertad del sujeto respecto de sus propios intereses es obligarle a ejercer el bien de una manera determinada, representando un verdadero contrasentido justificar que la restricción de la libertad personal, en un Derecho penal liberal, pueda llevarse a cabo para proteger al individuo libre. Por lo anterior, si, pese a todo, aún pretende restringirse la disponibilidad, hacerlo en nombre de la libertad representaría una justificación realmente falta de honestidad.

\section{Problemas en torno a la vida y salud individual}

Como veníamos sosteniendo, según la concepción tradicional y mayoritaria de la disponibilidad, habrían supuestos bienes jurídicos que, no obstante ser individuales, se rotulan como indisponibles. Tal categorización resulta problemática en dos sentidos: primeramente, como es de intuirse, por negar directamente los fundamentos de la disponibilidad, lo que lógicamente precisa de fundamento plausible y suficiente para un tratamiento excepcional para algunos bienes jurídicos, como la vida y la salud e integridad individual, y uno diferente para otros, como los bienes jurídicos patrimoniales. En seguida, resulta incompatible con la noción misma de bien jurídico, pero de ello nos haremos cargo en el apartado cuarto de este trabajo, avocándonos a continuación del primero.

El primer caso problemático lo plantea el bien jurídico vida, atendido a que la amplia mayoría de la doctrina lo considera un bien jurídico individual, pero indisponible. En España, como apunta Mirentxu CorCoy, se discute si el reconocimiento constitucional -e internacional- del derecho a la vida genera un deber de vivir y, en consecuencia, que la vida sea indisponible $^{32}$. La jurisprudencia del Supremo Tribunal Constitucional español niega que de la Constitución española pueda extraerse un derecho a morir, dado que la incompatibilidad implícita de los conceptos vida y muerte obligaría a interpretar que en la Constitución sólo se protege el derecho a la

32 CORCOY BIDASOLO, Mirentxu: Manual de Derecho penal. Parte especial. Tirant lo Blanch, Madrid, $2^{\circ}$ ed, 2015. p. 47. 
$v$ vida $^{33}$. Esta posición está en línea con la doctrina tradicional española, que ha fundamentado que la vida, como bien jurídico, tiene un componente supraindividual que determina la concurrencia de una obligación del Estado de protegerla incluso en contra de la voluntad de su titular. Sin embargo, tal como defiende Corcoy, la vida es un bien jurídico personalísimo, de manera que el Estado sólo puede protegerlo ante la ausencia de consentimiento del titular, siempre y cuando atribuya la preponderancia que la dignidad y libertad merecen ${ }^{34}$.

Por su parte, RivacoBA ${ }^{35}$ planteaba que el poder o facultad de disposición de la vida por el Estado en exclusiva parece hallarse actualmente en franca crisis, con la abierta decadencia, por una parte, de la pena de muerte, que en muchos países ha llegado a su desaparición, y la lógica imposibilidad para aquél de disponer de la vida humana como sanción punitiva, y con la arrolladora imposición, por otra, del reconocimiento del derecho de objeción de conciencia y la consiguiente exención del servicio militar, que le impide contar con la vida humana como medio para asegurar o procurar mantener su propia existencia o para lograr su engrandecimiento. Aún más, la posición de garante del funcionario es limitada en el caso de las huelgas de hambre en el ámbito penitenciario, no debiendo alimentar forzosamente de manera automática, ni tampoco se hace reo de homicidio al no dar alimento coactivo, lo anterior, pues no existiría la obligación de no-impedir la muerte del que decide libremente prescindir de su vida ${ }^{36}$, lo que implicaría la impunidad de comportamientos omisivos. Estos casos son muestras de que el ordenamiento tiende a asignar mayor importancia a la libertad del individuo, en razón de su dignidad, incluso si el contenido de voluntad específico sea de lesión o puesta en peligro de la propia vida. En otras palabras, RivacoBa habla de la subjetivización de la disponibi-

33 Sin embargo, debe considerarse que el Código penal español concede relativa eficacia al consentimiento en los delitos de inducción y cooperación al suicidio - entre éstos, la eutanasia-, regulación que resulta compatible con un entendimiento de la vida como bien jurídico disponible, cuya disposición sin embargo se trata de un derecho personalísimo, de modo que se castiga al partícipe. En definitiva, el suicidio sería lícito y las conductas de participación ilícitas. Muñoz Conde señala que la impunidad del suicidio no significa indiferencia del ordenamiento jurídico frente a los actos de participación en él. MUÑOZ CONDE, Francisco: Derecho penal. Parte especial. Editorial Tirant lo Blanch, Valencia, 20 ${ }^{\circ}$ ed, 2015. p. 57.

34 CORCOY BIDASOLO, ob. cit., p. 47.

35 RIVACOBA, Manuel: "Cambio de sentido en la protección y el concepto penal de la vida humana". En: Doctrina penal, número 46/47, abril-septiembre de 1989. Ediciones Depalma, Buenos Aires, 1989. p. 287- 289.

36 DIEZ RIPOLLÉS, José Luis: “Eutanasia y Derecho”. En: Anuario de Filosofía del Derecho, № 12, Málaga, 1995. p. 83-114. 
lidad de la vida, en la que "queda garantizada frente al Estado la vida humana individual y concreta", y, debiera "considerarse un bien jurídico disponible por parte de su titular, debiéndose reconocer absoluta libertad de disposición"

Tras la decisión de un ordenamiento en orden a restar eficacia desincriminante al consentimiento del interesado se esconden consideraciones que no descansan ya en la esencia misma del bien jurídico sino en viejas concepciones autoritarias. El debate en torno de la eficacia del consentimiento se ha circunscrito tradicionalmente a objetos especialmente relevantes para el individuo tales como los mentados objetos vida o la salud e integridad corporal. Es decir, fuera de ese ámbito, no es problemático afirmar que el consentimiento posee efecto desincriminante, ya como causa de atipicidad, de justificación o bien por constituir una cancelación de la norma prohibitiva. Pero respecto de la vida, no sucede lo mismo. Para el caso español, la eficacia limitada que posee el consentimiento en este ámbito se ha fundamentado, en primer lugar, en la persistencia de valores éticos o religiosos y, en segundo lugar, en razones de política-criminal, derivados de la dificultad de probar, en muchos casos, que el consentimiento del titular haya sido un consentimiento libre y válidamente emitido ${ }^{38}$. Sobre lo primero, si bien el Derecho en la actualidad ya está formalmente desvinculado de concepciones religiosas, aún persiste una concepción común de la vida como un bien teñido por consideraciones morales, divinas o supraindividuales de las que hasta hoy no ha conseguido liberarse. MAGGIORE ilustra muy claramente esta visión al desarrollar la idea de que la vida es un bien sumo, no sólo para el individuo, sino para la sociedad y el Estado, como valor cualitativo y cuantitativo (demográfico), pues, habiendo sido dada al hombre por Dios, solo él podría quitársela, pudiendo también hacerlo el Estado sólo para fines supremos de la colectividad, más el individuo nunca podría convertirse en árbitro de su destrucción ${ }^{39}$.

Actualmente, la doctrina razona de una manera algo menos alarmante, afirmando que la vida no sería disponible por trascender el mero interés

37 CASAS BARQUERO, El consentimiento en el derecho penal. Universidad de Córdoba, Córdoba, 1987. p. 94.

38 CORCOY BIDASOLO, ob. cit., p. 47.

39 KIERSZENBAUM, Mariano: "El bien jurídico en el Derecho penal. Algunas nociones básicas desde la óptica de la discusión actual". En Lecciones y Ensayos, $\mathrm{N}^{\circ}$ 86, Buenos Aires, 2009. pp. 207-213. 
individual $^{40}$, -en palabras de WeLZeL-por encontrarse la tutela de la vida protegiendo, junto al interés individual, simultáneamente el interés públi$\mathrm{co}^{41}$, si se quiere, por fines demográficos, porque la nación necesita una población para desarrollarse, etc. ${ }^{42}$. Al respecto, este "componente supraindividual que determina la concurrencia de una obligación del Estado de protegerlo (el bien jurídico) en contra incluso de la voluntad de su titular" es "difícil de fundamentar, por cuanto, si son bienes jurídicos personalísimos, el deber constitucional del Estado de protegerlos decae en el momento en que el titular del derecho declina esa protección". Por ello, señala Corcoy que un amplio sector de la doctrina afirma la disponibilidad de la propia vida, basándose en la preponderancia de la dignidad y la libertad ${ }^{43}$, fundamentos, como vimos, de la disponibilidad.

Lo mismo ha ocurrido comúnmente con la salud e integridad corporal, que se consideran bienes jurídicos individuales. En Alemania, Italia, Austria, por ejemplo, las lesiones corporales son impunes si es que se realizan con el consentimiento del interesado, salvo que el hecho vaya en contra de las buenas costumbres. Por tanto, es de toda lógica concluir que, como apunta KINDHÄUSER, lo que se protege, en realidad, son las buenas costumbres, toda vez que aquí el fundamento del injusto recae únicamente en la protección de este bien colectivo ${ }^{44}$ cuya protección no se explica en absoluto mediante la tipificación de un delito que se supone afecta efectivamente intereses individuales. Por esto es que JESCHECK, refiriéndose a esta situación, sostiene que "la causa de justificación representada por el consentimiento resultaría relativizada de forma difícilmente sostenible en un Estado de Derecho si tuviera lugar la aplicación general del correctivo

40 LANGÓN, Miguel: Manual de Derecho penal. Editorial Del Foro, Montevideo, 2006. p. 313. En esta línea, Muñoz Conde recoge la opinión que en general se ha dado sobre la vida, enunciando que ésta "es objeto de protección en el ámbito penal incluso frente a la voluntad de su titular, que no tiene derecho a disponer sobre ella libremente y que, en consecuencia, no está legitimado para autorizar a los demás a que lo maten”. MUÑOZ CONDE, ob. cit., p. 57.

41 WELZEL, Derecho Penal Alemán, ob. cit., p. 139. De similar opinión, Kindhäuser, para quien la vida está en función del interés general (KINDHÄUSER, ob. cit., cfr. pp. 17 y ss.) y Fontán Balestra, refiriéndose a la eficacia del consentimiento sobre bienes disponibles, señala que "cuando esa tutela [penal] garantiza, además, un interés público o común, el consentimiento es irrelevante", tal como es el caso de la vida. FONTÁN BALESTRA, Carlos: Derecho Penal. Introducción y Parte general. Abeledo Perrot, Buenos Aires, 1998. p. 247.

42 CURBELO SOLARI, ob. cit., cfr. p. 108.

43 CORCOY BIDASOLO, ob. cit., p. 47

44 KINDHÄUSER, ob. cit., pp. 15 y 16. 
de las buenas costumbres, que vendría a someter al titular del bien jurídico a una tutela estatal intolerable" 45 .

Reconocer en la vida, en la salud individual e integridad corporal, en fin, en cualquier bien jurídico individual un interés estatal sería, como bien expresa KiERSZENBAUM, atribuirle al Estado una enorme "co-titularidad" de los bienes, que incluso se impone sobre la titularidad individual ${ }^{46}$. Desde una óptica liberal, el bien jurídico debiera responder ante todo al cometido de limitar el poder del Estado, por lo que de erigirse éste como titular de aquellos bienes jurídicos, tal función limitadora desaparecería o, peor aún, daría un giro en la dirección opuesta, transformándose en un instrumento útil para expandir el poder estatal. En este sentido, es interesante atender a la crítica de MAIER referida a que, al menos en estos casos, la idea del bien jurídico ha servido al Estado para confiscar el conflicto a la víctima ${ }^{47}$.

Identificado el problema de adjetivar al bien jurídico de indisponible, convengamos que la concepción de la vida y la salud e integridad individual como disponibles no es una propuesta que no reconozca límites, máxime teniendo presente que en la amplia mayoría de países la eutanasia ${ }^{48}$ constituye un supuesto de homicidio consentido o auxilio al suicidio. En otras palabras, no es problemático que un sistema penal, por razones de política criminal, decida limitar la disponibilidad. No obstante, recurrir a argumentos basados en la naturaleza de los bienes jurídicos en juego, en orden al cual habría algunos en esencia más valiosos que otros, y que los más valiosos no serían disponibles; o en que la eutanasia es castigada porque el consentimiento no podría ser probado, ante el deceso de paciente; en fin, no resultan suficientes para afirmar la indisponibilidad de la vida. Lo anterior, si tenemos presente que "[1]os límites a la eficacia deben buscarse en el derecho político, en el límite a la actividad punitiva del Estado en virtud del ámbito de privacidad individual"49, por un lado, y que se el homicidio consentido se convertiría un delito de sospecha, por otro. Sentada esa base, los límites que legítimamente se podrían establecer a la disponibilidad parecen

$45 \quad$ JESCHECK, ob. cit., p. 517.

$46 \quad$ KIERSZENBAUM, ob. cit., p. 212.

47 Ibídem. En esta línea, se ha planteado que "[1]a pretendida tutela de un bien jurídico más allá de la voluntad de su titular es un pretexto para penar un pragma no conflictivo". ZAFFARONI, Eugenio R., ALAGIA, Alejandro y SLOKAR, Alejandro: Derecho penal. Parte general. Editorial Ediar, Buenos Aires, $2^{\circ}$ edición, 2003. p. 499.

48 La mención a la eutanasia se justifica por ser un modo legítimo de disponer de la propia vida, o su fin.

49 ZAFFARONI, ALAGIA, SLOKAR, ob. cit., p. 520. 
ser una decisión proveniente únicamente de consideraciones político-criminales que garanticen la seguridad jurídica.

Lo anterior se funda en que, en ciertas circunstancias, sería verdaderamente difícil probar la concurrencia de los requisitos que otorgan eficacia al consentimiento. CorCOY ya ha señalado que podrían justificar estos límites las "razones de política-criminal, derivadas de la dificultad de probar, en muchos casos, que el consentimiento del titular haya sido un consentimiento libre y válidamente emitido. Los problemas de prueba sobre la concurrencia de un consentimiento no viciado podrían justificar en la regulación penal se parta de una presunción de ausencia de consentimiento libre y, en consecuencia, aun cuando sea con penas mínimas, castigar a los partícipes" ${ }^{\prime 50}$. Por tanto, la posibilidad irrestricta de disponer de los bienes jurídicos podría significar un aliciente criminógeno para aquel agente que, sin contar con el correspondiente consentimiento del interesado, efectúe una conducta delictuosa que, por esta vía, pudiese resultar impune injustificadamente. Sin embargo, castigar conductas de heterolesión consentida fundándolo en la sospecha de que el consentimiento no podrá ser probado resulta, a nuestro juicio, inconveniente, puesto que se castigarían situaciones en que tal consentimiento existe como si no existiera. En el fondo, castigar las formas de participación en el suicidio ajeno es establecer derechamente delitos de sospecha, en que existe el temor de que en aquellos actos no concurrió el consentimiento y se trata, en consecuencia, de un delito de homicidio o asesinato según corresponda.

Por ello, los límites al consentimiento no representan una consecuencia derivada de la esencia de los bienes jurídicos, sino que son, finalmente, medidas de política criminal que el legislador tendrá que establecer teniendo en cuenta la importancia y los fundamentos de la disponibilidad frente al temor de que exista un consentimiento válido no susceptible de ser probado.

Con todo, por razones de seguridad jurídica podría ser prudente establecer en los códigos causas de justificación procedimentales, a saber, aquellas que autorizan un comportamiento que cumple con el procedimiento establecido en leyes ${ }^{51}$, v. gr., la regulación de la interrupción del embarazo en España ${ }^{158}$. En este sentido, el propio ordenamiento jurídico es el que debe establecer la forma en que se puede disponer de la vida, y castigar

50 CORCOY BIDASOLO, ob. cit., p. 47.

51 HASSEMER, Winfried y LARRAURI, Elena: Justificación material y justificación procedimental en el Derecho penal. Editorial Tecnos, Madrid, 1997. p. 10. 
exclusivamente aquellas conductas que no cumplen, en rigor, dicho procedimiento $^{52}$.

En fin, pareciera que los argumentos en pos de la indisponibilidad de la vida y la salud e integridad individual no son satisfactorios, toda vez que su disposición queda entregada enteramente a su titular, cada una de las personas individualmente consideradas. Diferente es la idea que sostenga que, político criminalmente, es aconsejable establecer y regular procedimientos para manifestar el consentimiento tratándose de determinados bienes jurídicos, como las referidas vida y salud e integridad individual.

\section{La disponibilidad en los bienes jurídicos}

En todas las teorías acerca de la naturaleza jurídica del consentimiento se halla una relación directa entre la disponibilidad y el concepto de bien jurídico, noción sobre la cual ha existido gran discusión, más cuya revisión excede con mucho las pretensiones del presente trabajo. Por ello, nos limitaremos a trabajar sobre la base de lo que estos autores estiman una correcta comprensión del bien jurídico, a partir de la caracterización que propone ZAFFARONI, muy valiosa por destacar la íntima vinculación existente entre el bien jurídico y la disponibilidad. Al concebirlo como la "relación de disponibilidad de un sujeto con un objeto (...)", pone de relieve el núcleo esencial del bien jurídico, que no se encontraría, en rigor, en el objeto (bien) mismo, sino precisamente en la relación de disponibilidad que su titular tiene con tal objeto ${ }^{53}$.

Esta relación de disponibilidad existe entre un sujeto -titular del bien jurídico- y un objeto jurídico-penalmente relevante, el cual estaría conformado por aquellos derechos e intereses que la sociedad y el ordenamiento estiman como valiosos y dignos de fundar la tutela penal. Tal objeto es valioso precisamente en función de su relación con el sujeto para el cual tiene valor. Por ello, el bien jurídico es algo más que el puro objeto desvinculado de su relación (de disponibilidad) con el sujeto, siendo precisamente dicha relación lo que el ordenamiento efectivamente tutela, entendiendo que el bien jurídico "existe en función de los intereses individuales" ${ }^{54}$. A mayor abundamiento, un bien jurídico se verá lesionado o puesto en peligro exclu-

$52 \quad$ Sin embargo, una regulación de esta naturaleza difícilmente podría eximir de responsabilidad las muertes por piedad, por lo que constituye tan sólo un pequeño avance en lo que efectiva disposición del bien vida se refiere.

53 ZAFFARONI, ALAGIA, SLOKAR, ob. cit., p. 489.

54 CANCIO MELIÁ y PÉREZ MANZANO, ob. cit, p. 101. 
sivamente cuando se atente contra dicha relación existente entre el sujeto y el objeto. Así, el bienestar físico o psíquico de un particular como objeto valioso no constituye bien jurídico en sí mismo sino únicamente en virtud de la relación de disposición que vincula a tal objeto con un sujeto ${ }^{55}$. Entender, por el contrario, que lo protegido es el mero objeto sin relación con su titular, es concebir que el Estado está facultado para imponer a los individuos la forma de aprovechar o ejercer sus bienes jurídicos en un sentido ordenado y no como éstos estimen conveniente, visión cuyo autoritarismo intrínseco parece controvertir el espíritu de un Estado democrático de Derecho.

Por otro lado, siguiendo estos postulados deberíamos todavía hacernos cargo de lo que sucede en la clasificación tripartita de los bienes jurídicos según su titular, que identifica los colectivos y estatales que, tradicionalmente, se han rotulado como indisponibles, considerándose disponibles únicamente los individuales $-\mathrm{y}$ no en todos los casos-. Sin embargo, un razonamiento tal confunde aquello respecto de lo cual se predica la disponibilidad, que no es el bien jurídico, sino el objeto que forma parte de aquél. Los motivos por los que se resta eficacia al consentimiento individual en relación con la ofensa de ciertos bienes o intereses colectivos o estatales no derivan de una supuesta indisponibilidad esencial de los bienes jurídicos, lo que no puede ser, sino del hecho que el interesado, en tales casos, no es el individuo sino otra entidad que, por motivos más vinculados a dificultades prácticas, seguridad jurídica o argumentos de política-criminal -en el caso de la comunidad indiscriminadamente considerada-, o en razón de una decisión anticipada sobre la disponibilidad por parte del titular -respecto de los bienes jurídicos estatales-, el ordenamiento asume que el interesado optará siempre por no menoscabar el objeto con el cual se halla vinculado. En efecto, pueden existir legítimas limitaciones a la disponibilidad, más de ello no es posible derivar ningún argumento contra el concepto de bien jurídico, pues, como afirma BACIGALUPO, éste no puede depender de la efectiva protección penal que se le dé en un ordenamiento determinado ni del alcance con que éste le permita al titular disponer de él ${ }^{56}$.

$55 \quad$ En palabras de Roxin, "bien jurídico y poder de disposición sobre el bien jurídico forman no sólo una unidad, sino que objeto de disposición y facultad de disposición son, en su relación mutua, de por sí, el bien jurídico protegido en el tipo”. ROXIN, ob. cit., p. 518.

56 BACIGALUPO, Enrique: Hacia el nuevo Derecho penal. Hammurabi, Buenos Aires, 2008. p. 357. 
Del razonamiento hasta aquí expuesto se sigue que la relación de disponibilidad, en todos sus campos operativos y respecto de todas sus acepciones, si se quiere, resulta ser un presupuesto del concepto mismo de bien jurídico. Por consiguiente, siguiendo a ZaFfaroni, esta esencia del bien jurídico no es, bajo ningún supuesto, incompatible con la renuncia a la protección jurídico-penal del objeto, sino más bien una modalidad de franco ejercicio del bien jurídico ${ }^{57}$. Así, si bien con la disposición puede ciertamente verse afectado el objeto del bien jurídico (v. gr. la salud individual como objeto específico de tutela), no es menos cierto que ésta importa de entrada excluir la afectación al bien jurídico mismo.

Por ello, el principio de ofensividad es también útil para fundamentar la disponibilidad, junto a la dignidad y libertad. Es fundamental comenzar por notar que, en su cometido político, el bien jurídico históricamente tuvo su origen en concepciones liberales dirigidas a proteger la libertad personal frente a la arbitrariedad del poder para asegurar, en el fondo, que el delito no obedezca al capricho del legislador ${ }^{58}$. Como sabemos, para que una conducta sea delictiva, además de ser un comportamiento externo descrito en una ley formal previa, debe dañar u ofender el bien específicamente protegido por la norma ${ }^{59}$. Señala Roxin que un sector importante de la doctrina considera que el consentimiento hace desaparecer el objeto de tutela, que consistiría en la libertad de disposición del sujeto sobre determinado objeto o sobre el valor que dicho objeto tiene para su titular ${ }^{60}$. ZAFFArONI, por su parte, sostiene que la disposición implicaría el ejercicio de un derecho subjetivo y esto demostraría que con ella no habría afectación del bien

$57 \quad$ Así, la disponibilidad "no puede ser renuncia sino ejercicio del derecho que la ley protege, o sea, no es precisamente renuncia a la protección, sino actuación a su amparo". ZAFFARONI, Eugenio Raúl: Tratado de Derecho penal. Parte general. Ediar, Buenos Aires, 1981. p. 519.

58 BAJO FERNÁNDEZ, Miguel: "El Derecho penal: concepto y principios". En: Lascuraín Sánchez, J. A. (coord) Introducción al Derecho penal. Civitas, Navarra, 2015. p. 42.

59 CURBELO SOLARI, ob. cit., p. 91, tomando las palabras de Fernández en FERNÁNDEZ, Gonzalo: Bien Jurídico y Sistema del Delito. B de F, Montevideo-Buenos Aires, 2004. p. 8., quien plantea que "la tipicidad no significa solamente la exacta correspondencia entre la conducta histórica y la descripción literal abstracta del tipo legal, sino que a ello debe adicionársele, como segundo elemento de la tipicidad, la afectación del bien jurídico protegido".

60

ROXIN, ob. cit., p. 517. 
jurídico ${ }^{61-62}$. Si bien es cierto que el consentimiento no podría excluir la efectiva afectación del objeto, cuando el titular del bien jurídico ha brindado su consentimiento no puede configurarse lesión alguna al bien jurídico. Por tanto, en consideración al principio de exclusiva protección de bienes jurídicos, la conducta del agente mal podría ser castigada si el propio titular de un objeto decide disponer de él cumpliendo con los requisitos que el consentimiento exige; no estaría lesionando su bien jurídico, sino más bien ejerciendo la autonomía que le corresponde ${ }^{63}$.

En última instancia, si el derecho penal debe proteger aquella relación de disponibilidad que un sujeto tiene con aquellos derechos e intereses jurídicamente relevantes, no puede llamarse "protección" a la intervención estatal en contra de la voluntad del titular del bien jurídico, pues ello constituye más bien un atentado contra el libre ejercicio del bien jurídico $o$, si se quiere, un ataque a éste ${ }^{64}$. En otras palabras, el Estado protege al bien jurídico cuando castiga al agente que obra en contra o sin la voluntad del interesado, pero no lo protege cuando ordena a los sujetos usar el bien jurídico en un sentido determinado, puesto que el castigo de la conducta que el interesado ha consentido implica el castigo de una conducta que no vulnera al individuo, sino la voluntad estatal, atentado que representa precisamente aquello que el principio de exclusiva protección de bienes jurídicos pretende evitar.

62 En la posición contraria, Kindhäuser plantea que no puede dejar de considerarse como un menoscabo la alteración negativa del bien, por cuanto si aceptásemos que la alteración de un bien podría no representar un menoscabo, sería conceptualmente imposible asociar consecuencias jurídicas a alteraciones perjudiciales consentidas por el titular. KINDHÄUSER, ob. cit., p. 29. En nuestra opinión, este razonamiento yerra en tanto confunde el fundamento de las consecuencias jurídicas que ha de producir una alteración consentida por el titular del bien jurídico, pues la razón que subyace a la producción de tales consecuencias no es la ilicitud del hecho sino más bien una institución diferente, que es la prohibición del enriquecimiento sin causa.

63 CANCIO MELIÁ y PÉREZ MANZANO, ob. cit., p. 101.

64 Por ello, con razón Zaffaroni expresa que "cuando se pretende separar al bien jurídico de su titular, no se hace otra cosa que destruir o negar el concepto mismo de bien jurídico (...) Cualquier intervención punitiva alcanza un grado intolerable de irracionalidad cuando pretende que el habitante use el bien jurídico sólo en determinada forma". En ZAFFARONI, ALAGIA, SLOKAR, ob. cit., p. 499. 


\section{Resumen conclusivo}

A partir de la constatación de la poca atención por parte de la doctrina que ha recibido esta categoría, hemos intentado caracterizarla en su forma habitual y realizar algún aporte en la delimitación de su concepto y fundamentos, para luego abordar el problema de ciertos bienes jurídicos que, pese a no haber duda de que formalmente son de titularidad individual, se predica de ellos que son indisponibles. Por ello, en base a la propuesta de ZAFFARONI sobre los bienes jurídicos, creemos que es posible armonizar una comprensión de éstos, particularmente los individuales, como disponibles por esencia, sin perjuicio de que existan razones, no ya derivadas de la consistencia misma del bien jurídico, sino más bien de orden práctico, que permiten a un ordenamiento jurídico limitar la disponibilidad. En fin, para concluir, solo resta mencionar que la decisión de titular esta contribución como "La disponibilidad en los bienes jurídicos" se funda en que la preposición que antecede los bienes jurídicos busca ilustrar el planteamiento del problema, cual es proponer un giro en la concepción de la disponibilidad, pasando de la visión tradicional que la considera una nota accidental del bien jurídico, como disponibilidad o indisponibilidad de ellos, hacia una visión de la disponibilidad como parte esencial del concepto mismo de bien jurídico, es decir, ínsita en ellos.

\section{Bibliografía}

BACIGALUPO, Enrique: Hacia el nuevo Derecho penal. Hammurabi, Buenos Aires, 2008.

BAJO FERNÁNDEZ, Miguel: "El Derecho penal: concepto y principios". En Lascuraín Sánchez, J. A. (coord.), Introducción al Derecho penal, Civitas, Navarra, $2^{\circ}$ ed., 2015.

BERLIN, Isaiah: Cuatro ensayos sobre la libertad. Alianza Editorial, Madrid, 1993.

CANCIO MELIÁ, M. y PÉREZ MANZANO, M.: "Principios del Derecho penal". En Lascuraín Sánchez, J. A. (coord.), Introducción al Derecho penal, Civitas, Navarra, $2^{\circ}$ ed., 2015.

CANCIO MELIÁ, Manuel: Conducta de la Víctima e Imputación objetiva en el Derecho penal. Editorial J. M. Bosch, Madrid, 1 ed., 1998. 
CASAS BARQUERO, El consentimiento en el derecho penal. Universidad de Córdoba, Córdoba, 1987.

CEREZO MIR, José: Derecho penal. Parte General. Ed. Tecnos, Montevideo-Buenos Aires, 2008.

CLAPHAM, Andrew: Human Rights Obligations of Non-State Actors. Editorial Oxford, Oxford, 2006.

CORCOY BIDASOLO, Mirentxu: Manual de Derecho penal. Parte especial. Tirant lo Blanch, Madrid, $2^{\circ}$ ed., 2015.

CURBELO SOLARI, Ignacio: "Problemática sobre la disponibilidad de los Bienes Jurídicos Individuales y Responsabilidades Emergentes". En Revista de la Facultad de Derecho, № 32, Montevideo, 2012.

DIEZ RIPOLLÉS, José Luis: "Eutanasia y Derecho". En: Anuario de Filosofía del Derecho, N 12, Málaga, 1995.

FERNÁNDEZ, Gonzalo: Bien Jurídico y Sistema del Delito. B de F, Montevideo-Buenos Aires, 2004.

FONTÁN BALESTRA, Carlos: Derecho Penal. Introducción y Parte general. Abeledo Perrot, Buenos Aires, 1998.

HASSEMER, Winfried y LARRAURI, Elena: Justificación material y justificación procedimental en el Derecho penal. Editorial Tecnos, Madrid, 1997.

JAKOBS, Günther: Derecho Penal. Parte general, Fundamentos y teoría de la imputación, $2^{\circ}$ ed., trad. Joaquín Cuello Contreras y José Luis Serrano González de Murillo. Marcial Pons, Madrid, 1997

JESCHECK, Hans-Heinrich: Tratado de Derecho Penal. Parte general, trad. S. Mir Puig y F. Muñoz Conde. Bosch, Barcelona, 1981, t. I.

JIMÉNEZ DE ASÚA, Luis: Tratado de Derecho penal. Losada, Buenos Aires, 1952, t. IV

KIERSZENBAUM, Mariano: "El bien jurídico en el Derecho penal. Algunas nociones básicas desde la óptica de la discusión actual”. En: Lecciones y Ensayos, № 86, Buenos Aires, 2009.

KINDHÄUSER, Urs: Teoría de las normas y sistemática del delito. Ara editores, Lima, 2008. 
LANGÓN, Miguel: Manual de Derecho penal. Editorial Del Foro, Montevideo, 2006.

LUTHER, Jörg: "Razonabilidad y dignidad humana". En: Revista de Derecho Constitucional Europeo, Universidad de Granada, España, año 4, núm. 7, enero-junio de 2007.

MAURACH, R., ZIPF, H.: Derecho Penal. Parte general, trad. $7^{\circ}$ ed. por Jorge Bofill Genzsch y Enrique Aimone Gibson. Astrea, Buenos Aires, 1994

MEZGER, Edmund: Derecho penal. Libro de Estudio. Parte general. Editorial Bibliográfica Argentina, Buenos Aires, 1958.

MEZGER, Edmund: Derecho penal. Parte general. trad. $6^{\circ}$ ed. alemana por Conrado A. Finzi. Editorial Bibliográfica Argentina, Buenos Aires, 1954. t. I.

MILL, John-Stuart: Sobre la Libertad. Alianza Editorial, Madrid, 2004.

MIR PUIG, Santiago: El Derecho penal en el Estado Social y Democrático de Derecho. Ariel, Barcelona, 1994.

MUÑOZ CONDE, Francisco: Derecho penal. Parte especial. Editorial Tirant lo Blanch, Valencia, 20 ed., 2015.

NOGUEIRA, Humberto: Dignidad de la persona, derechos fundamentales, bloque constitucional de derechos y control de convencionalidad, p. 1-2. En http://www.crdc.unige.it/docs/articles/Dignidad.pdf

PECES-BARBA MARTÍNEZ, Gregorio: La dignidad de la persona desde la Filosofía del Derecho. Editorial Dykinson, Madrid, 2 ed., 2004.

PETTIT, Philip: Republicanismo. Una teoría de la libertad y del gobierno, trad. Toni Domènech. Paidós, Barcelona, 1999.

RIVACOBA, Manuel de: "Orden político y orden penal". En: Revista Chilena de Derecho, vol. 22, º2, 1995. pp. 201-212.

RIVACOBA, Manuel: "Cambio de sentido en la protección y el concepto penal de la vida humana". En: Doctrina penal, número 46/47, abrilseptiembre de 1989, Ediciones Depalma, Buenos Aires, 1989.

ROXIN, Claus: Derecho penal. Parte general, 2 vols., trad. $2^{\circ}$ ed. alemana por Diego- Manuel Luzón Peña, Miguel Díaz y García Conlledo y Javier de Vicente Remesal. Civitas, Madrid, 1997, t. I. 
STRATENWERTH, Günter: Derecho penal. Parte general I. El hecho punible, trad. $4^{\circ}$ ed. alemana por Manuel Cancio Meliá y Marcelo A. Sancinetti. Hammurabi, Buenos Aires, 2008

WELZEL, Hans: Derecho penal. Parte general, trad. de Carlos Fontán Balestra, Roque. Depalma, Buenos Aires, 1956

WELZEL, Hans: Derecho Penal Alemán. Editorial Jurídica de Chile, Santiago, $11^{\circ}$ edición, 1976

Wessels, Johannes: Derecho penal. Parte general, trad. $6^{\circ}$ ed. alemana por Conrado A. Finzi. Ediciones Depalma, Buenos Aires, 1980

ZAFFARONI, Eugenio R., ALAGIA, Alejandro $y$ SLOKAR, Alejandro: Derecho penal. Parte general. Editorial Ediar, Buenos Aires, $2^{\circ}$ edición, 2003.

ZAFFARONI, Eugenio Raúl: Tratado de Derecho penal. Parte general. Ediar, Buenos Aires, 1981. 
